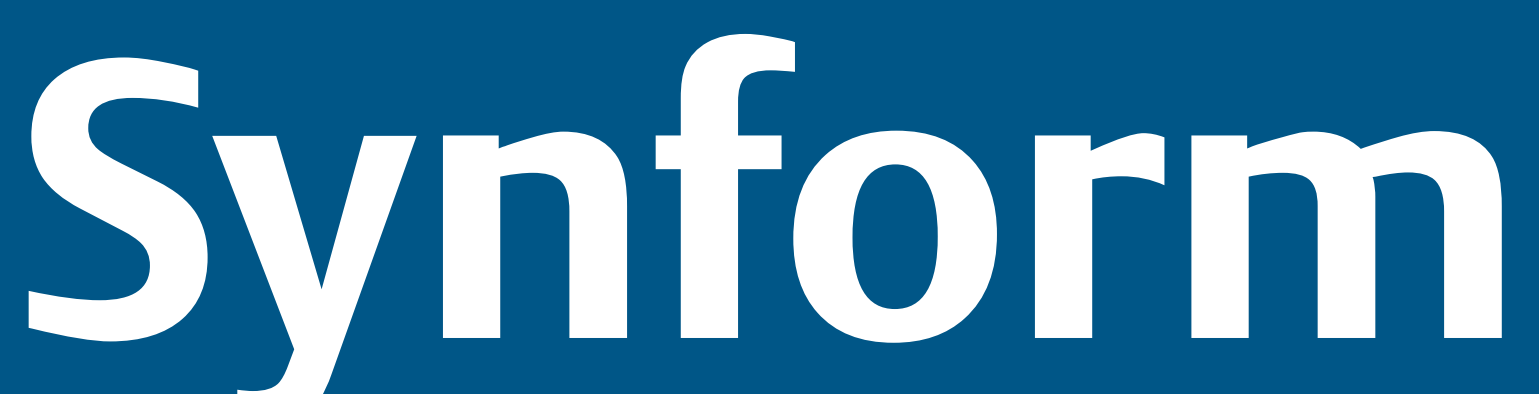

People, Trends and Views in Chemical Synthesis

$2021 / 02$

Migratory Functionalization of Unactivated Alkyl Bromides for Construction of All-Carbon Quaternary Centers via Transposed tert-CRadicals

Highlighted article by C. Zhu, Z.-Y. Liu, L. Tang, H. Zhang, Y.-F. Zhang, P. J. Walsh, C. Feng

Mn (1.5 equiv)

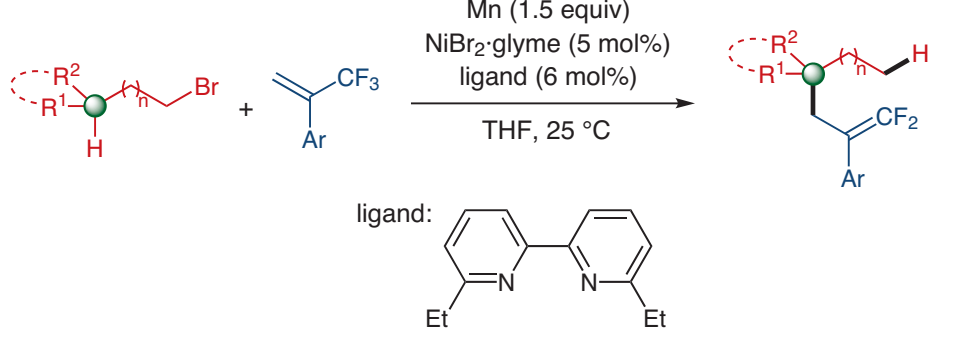

\title{
Contact
}

Your opinion about Synform is welcome, please correspond if you like:

marketing@thieme-chemistry.com
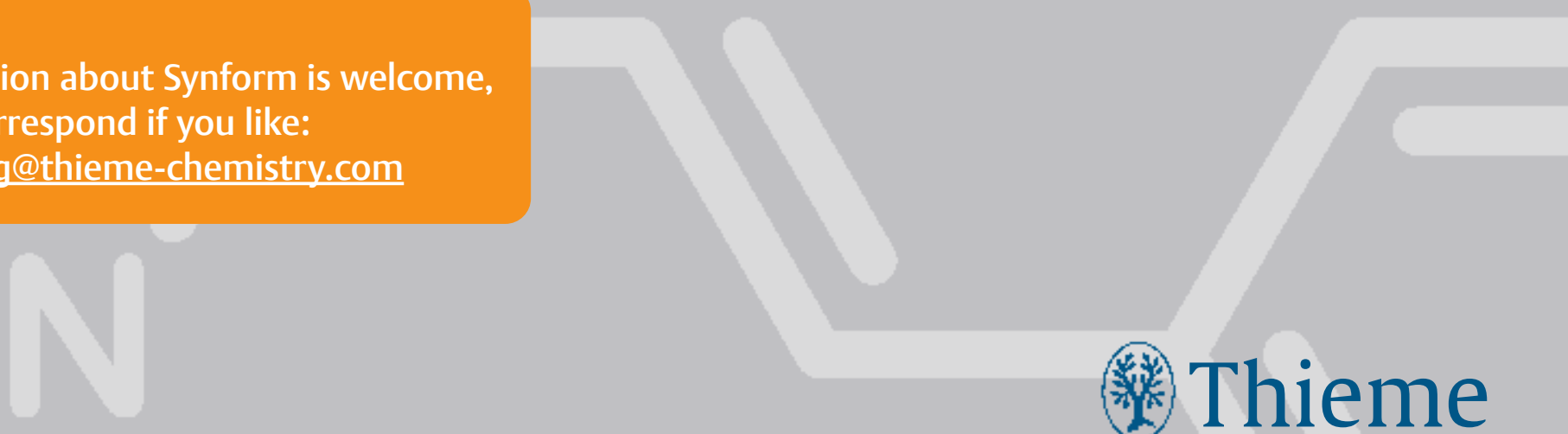


\section{Dear Readers,}

Almost five years later, Brexit is finally done. The United Kingdom is now effectively out of the European Union. For a slim majority of the people who voted in the 2016 Referendum it will be a day of joy, a glorious day. For many others - and certainly for most people in the EU - it is a day of great sadness. But we remain united here in the Old Continent, as we know that the EU Project is about peace, cooperation, welfare, education and culture, about promoting social equality and justice, not just about economy. Together we are stronger than divided, and this is particularly true for science and research. Brexit will necessarily create barriers between European research and UK research, regardless of the will and determination of scientists on both sides of the Channel to continue to work together, and the apparent possibility for UK scientists to continue to be involved in the EU Horizon Framework programmes. But it won't be the same anymore, partly because of physical, political and administrative barriers, but also because the UK is no longer part of the European Project. The UK has even pulled out from the glorious Erasmus programme, which has done so much in terms of promoting the exchange of the best undergraduate students between Europe and the UK, with massive long-term benefits for everyone involved. Now Brexit has split us, and this is going to create distance and diffidence on both sides, with a detrimental knock-on effect for every possible aspect of our lives, including scientific cooperation. I know it is difficult, but I really do hope - one day to see the United Kingdom, if not my beloved Scotland alone, back together with the rest of Europe, at least in some form. It would be great for science, but even greater for continuing and strengthening the European dream of creating a more peaceful, prosperous and fair world from the ashes of World War II. Personally, I believe Brexit is a tragic and terrible mistake, whose true consequences are still difficult to predict.

This February 2021 issue of SYNFORM starts with a Literature Coverage article on a novel method to achieve the synthesis of peptide-boronic acids, which are important peptide mimics with applications in drug discovery, developed by C. D. P. Klein (Germany). The next article covers a new approach to $\alpha$-diketones designed and

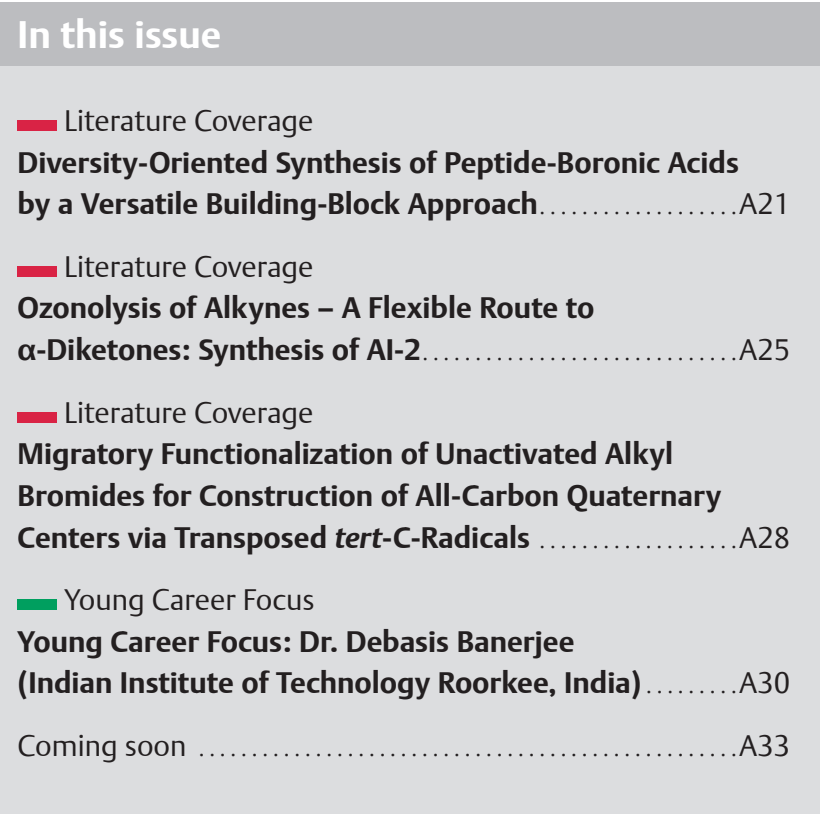

validated by the lab of G. A. Kraus (USA). The third article reports on a novel strategy to achieve the synthesis of all-carbon quaternary centers by exploiting radicals generated from unactivated alkyl bromides, according to the method jointly designed and developed by P. J. Walsh (USA) and C. Feng (P.R. of China). The issue is completed by a new interesting Young Career Focus interview, this time with D. Banerjee (India).

I would like to close this Editorial with a thought for Vic Snieckus, who left us at the end of 2020. Vic was not just an extraordinary chemist, teacher and mentor, but also a brilliant, entertaining and enthusiastic person, as well as one of the fathers of SYNLETT. We will sorely miss you Vic; goodbye my friend.

Enjoy your reading!

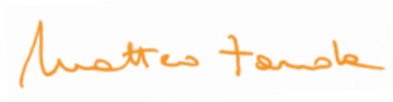

\section{Contact}

If you have any questions or wish to send feedback, please write to Matteo Zanda at: synform@outlook.com 


\title{
Diversity-Oriented Synthesis of Peptide-Boronic Acids by a Versatile Building-Block Approach
}

\author{
Chem. Sci. 2020, 11, 9898-9903
}

Serine proteases fulfil multiple roles in biology, ranging from digestive functions in humans to the replication of viruses. The inhibition of these enzymes can therefore induce numerous pharmacological effects. The work of Professor Christian Klein's group at Heidelberg University (Germany) has been motivated by their interest in peptide-boronic acids (PBAs) as serine protease inhibitors. "Our focus is on viral serine proteases, such as from the dengue, Zika, and West Nile viruses, where peptide-boronic acids were instrumental in the determination of crystal structures, ${ }^{1,2}$ " said Professor Klein, who continued: "However, the synthesis of these peptide-boronic acids from our group was highly challenging, involving multiple steps and encountering obstacles caused by, for example, difficulties in removing the pinanediol or pinacol protecting groups from the boronic acid function."
As shown in Figure 1, much progress has been made in recent years both in the solution-phase synthetic access towards borono-peptide building blocks and in their application in solid-phase synthesis. ${ }^{3-13}$ "Nevertheless, only a few years ago, our work in this field involved challenging and tedious synthetic pathways, for example in the synthesis of a trimeric peptide-boronic acid with basic side-chain functionalities, which was designed as a covalent-reversible inhibitor of flaviviral proteases," commented Professor Klein. The group therefore considered it highly worthwhile to devise novel approaches towards this class of compounds. A first step was the use of 1-glycerol PS resin, commercially available at a reasonable cost, to serve as anchoring point for the boronic acid moiety during solid-phase synthesis. ${ }^{10}$ Next, the group addressed the frustrating issue of deprotection, that is, the

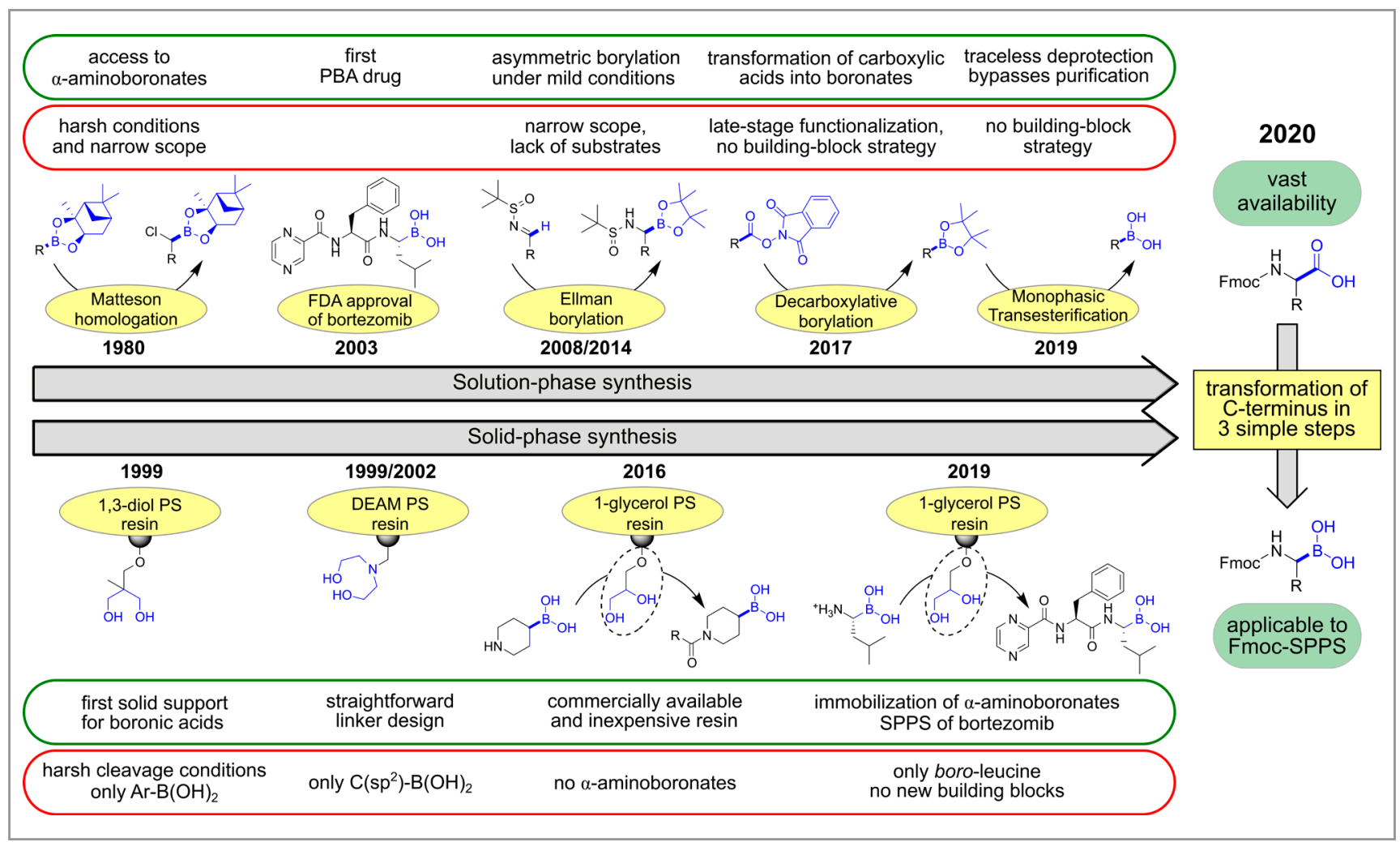

Figure 1 Milestones for the development of diversity-oriented PBA synthesis ${ }^{3-13}$ 
removal of the pinanediol or pinacol group from the boronic acid. Professor Klein explained: "The main problem here is the separation of polar products and reactants - which was frequently impossible using routine methods such as chromatography and liquid-liquid extraction - and the equilibrium of the deprotection reaction. Considering the volatility of numerous small-molecule boron compounds, it was envisaged that an orthogonal approach involving evaporation of reactants and products could be pursued. We were fortunately able to identify methyl boronic acid as a reactant with suitable chemical and physical properties for volatility-driven deprotection, which yields the volatile methyl boronic esters of pinanediol or pinacol, so that all undesired materials can be removed by evaporation. ${ }^{13}$ "

Addressing the next bottleneck towards a facile synthesis of peptide-boronic acids, the group turned their attention to the scarce availability of $\alpha$-amino boronic acid building blocks.
"The following work can be regarded as a logical combination and extension of previously established methods: it was discovered that Fmoc-protected NHPI esters of commercially available $\alpha$-amino acids are susceptible to the decarboxylative borylation described by the Baran group. ${ }^{11}$ However, the obtained Fmoc- $\alpha$-aminoboronates lacked stability during chromatography and liquid extraction was not feasible to remove the excess of borylation reagent $B_{2}$ pin $_{2}$. Two workup procedures were established to circumvent the issue of purification," explained Professor Klein. He continued: "Furthermore, the subsequent deprotection of pinacol esters with methylboronic acid was optimized to conditions that are suitable for a direct lyophilization after full conversion. Thus, pure Fmoc-protected $\alpha$-aminoboronic acids were obtained in three simple steps, that are readily employable in solid-phase synthesis. Using this approach, it is now possible to obtain in good yields, and using routine equipment and reactants,

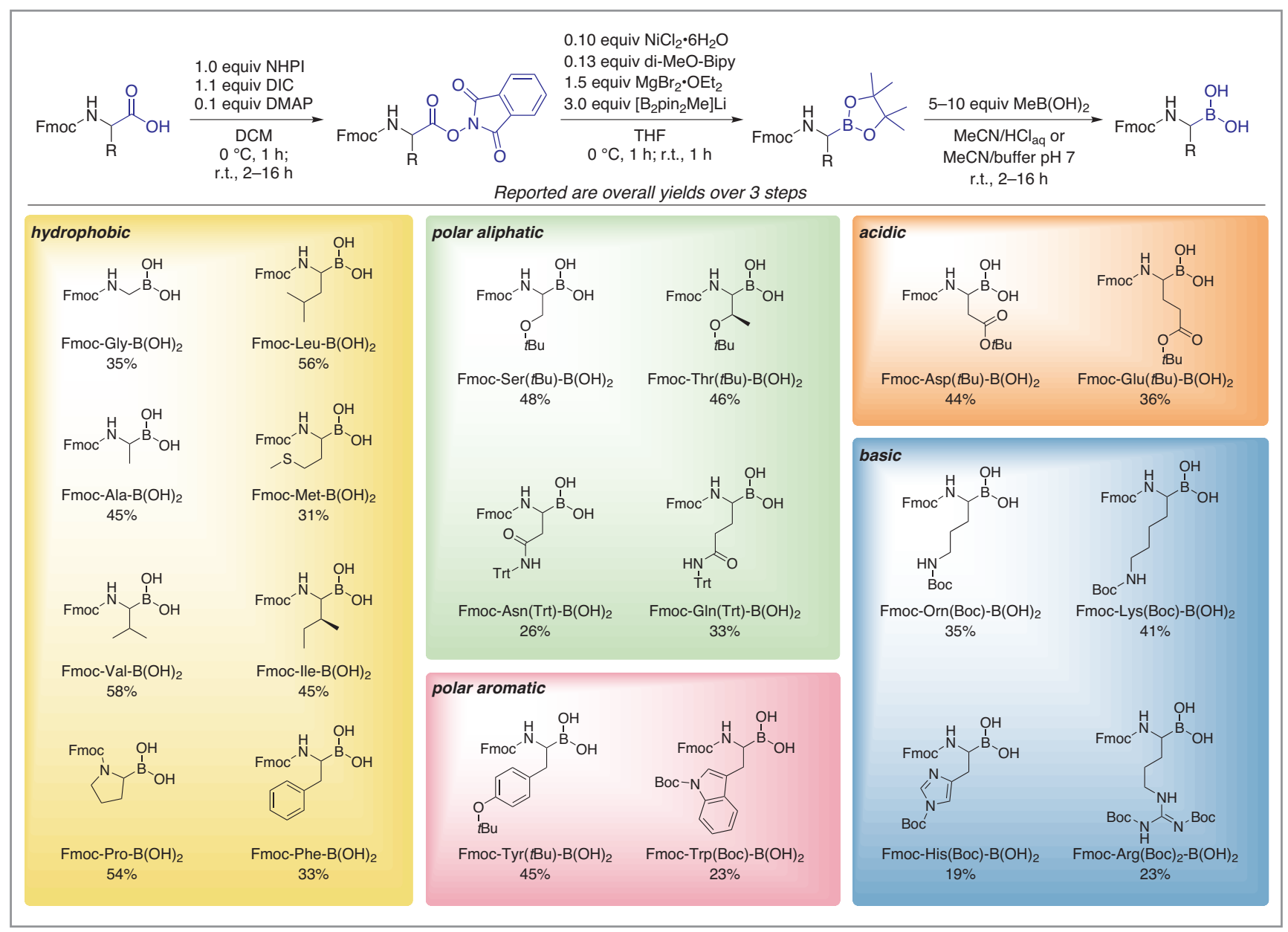

Scheme 1 Access to Fmoc- $\alpha$-aminoboronates and overall yields 
boron analogues of all proteinogenic amino acids with the exception of cysteine (Scheme 1). These can easily be utilized further in the solid-phase construction of C-terminal peptideboronic acids."

The group is optimistic that the presented synthetic methodology will enable them and others to pursue the synthesis of peptide-boronic acids with significantly improved productivity, thus opening a door towards the exploration of this as-yet largely unmapped chemical territory. Professor Klein concluded: "The biomolecular interaction potential of this class of compounds and their utility as chemical precursors for further synthetic steps make this a very appealing field for biological and chemical applications."

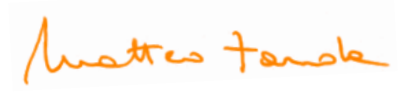

\section{REFERENCES}

(1) C. Nitsche, L. Zhang, L. F. Weigel, J. Schilz, D. Graf, R. Bartenschlager, R. Hilgenfeld, C. D. Klein J. Med. Chem. 2017, 60, 511-516.

(2) J. Lei, G. Hansen, C. Nitsche, C. D. Klein, L. Zhang,

R. Hilgenfeld Science 2016, 353, 503-505.

(3) D. S. Matteson, D. Majumdar J. Am. Chem. Soc. 1980, 102, 7588-7590.

(4) B. Carboni, C. Pourbaix, F. Carreaux, H. Deleuze,

B. Maillard Tetrahedron Lett. 1999, 40, 7979-7983.

(5) M. Gravel, K. A. Thompson, M. Zak, C. Bérubé, D. G. Hall

J. Org. Chem. 2002, 67, 3-15.

(6) D. G. Hall, J. Tailor, M. Gravel Angew. Chem. Int. Ed. 1999, 38, 3064-3067.

(7) A. Paramore, S. Frantz Nat. Rev. Drug Discov. 2003, 2, 611-612.

\section{About the authors}

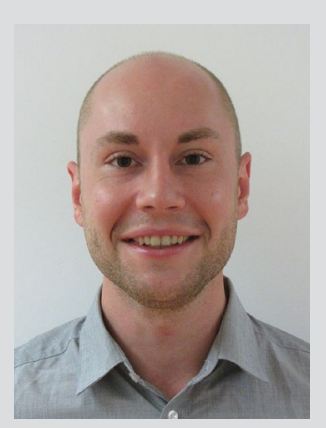

S. P. A. Hinkes
Stefan P. A. Hinkes graduated in pharmacy in 2014 at the University of Marburg (Germany) and obtained his M.Sc. in chemistry in 2016 under the guidance of Prof. Torsten Steinmetzer, also at the University of Marburg (Germany). He was a fellow of the German Academic Scholarship Foundation (Studienstiftung des deutschen Volkes) from 2013 to 2015. He is currently carrying out his PhD studies under the supervision of Prof. Christian Klein at the Institute of Pharmacy and Molecular Biotechnology (IPMB) at the University of Heidelberg (Germany). His research interests are focused on innovative methods for the synthesis of boronic acids, particularly peptide-boronic acids.

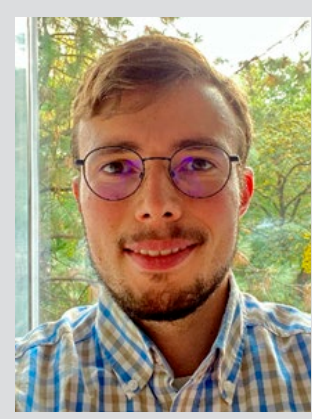

Severin Kämmerer graduated in pharmacy at the University of Regensburg (Germany). He has been licensed to practice pharmacy since 2018. Currently he works under the supervision of Professor Christian Klein at the IPMB, University of Heidelberg (Germany). During his PhD studies, funded by the German Academic Scholarship Foundation (Studienstiftung des deutschen Volkes), he

is focusing his research on the inhibition of bacterial quorum sensing by boronic acids and natural products.

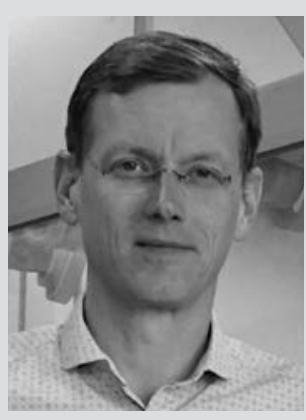

Prof. C. Klein
Christian Klein studied pharmacy at Bonn University (Germany) and ETH Zürich (Switzerland) and received practical training as an intern at Bayer AG (Germany). Following military service, he did research on his $\mathrm{PhD}$ topic at the University of Illinois at Chicago (USA) and Bonn University under the guidance of Profs. A. J. Hopfinger and Prof. U. Holzgrabe, respectively. This was followed by postdoctoral stays at ETH and Saarland University (Germany). He successfully applied for an Emmy Noether Junior group and received two offers for full professorships. Since 2007 he is professor of Pharmaceutical Chemistry at Heidelberg University (Germany). In 2012, he was elected as managing director of the IPMB. His research interests include antiviral and antibacterial drugs, CNS-active compounds and research on evolving strategies and scaffolds in medicinal chemistry, such as boronic acids. 
(8) A. W. Buesking, V. Bacauanu, I. Cai, J. A. Ellman J. Org. Chem. 2014, 79, 3671-3677.

(9) M. A. Beenen, C. An, J. A. Ellman J. Am. Chem. Soc. 2008, 130, 6910-6911.

(10) M. A. M. Behnam, T. R. Sundermann, C. D. Klein Org. Lett. 2016, 18, 2016-2019.

(11) C. Li, J. Wang, L. M. Barton, S. Yu, M. Tian, D. S. Peters, M. Kumar, A. W. Yu, K. A. Johnson, A. K. Chatterjee, M. Yan, P. S. Baran Science 2017, 356, eaam7355.

(12) B. E. Daniels, C. E. Stivala RSC Adv. 2018, 8, 3343-3347.

(13) S. P. A. Hinkes, C. D. P. Klein Org. Lett. 2019, 21, 30483052. 


\section{Ozonolysis of Alkynes - A Flexible Route to $\alpha$-Diketones: Synthesis of Al-2}

Org. Lett. 2020, 22, 7424-7426

$\alpha$-Diketones are useful substrates in the preparation of heterocyclic compounds and have a number of other applications in organic synthesis. Alkynes can be oxidized to $\alpha$-diketones using a range of different experimental conditions, but all these methods invariably make use of metals such as ruthenium, permanganate or mercuric salts. A more flexible, environmentally friendly and economic conversion of alkynes into $\alpha$-diketones would represent a breakthrough in the preparation of these compounds.

Professors Larry Halverson and George Kraus from Iowa State University (Ames, USA) are part of an interdisciplinary team supported by the US Department of Energy for developing an instrument to detect and quantify microbial metabolites and plant proteins secreted into the soil surrounding plant roots. Recently, their group have identified ozonolysis of alkynes as a highly convenient and versatile entry to structurally diverse $\alpha$-diketones. Professor Kraus commented: "The new synthetic route enables studies to assess the role of an inter-species quorum-sensing signal molecule furanosyl borate diester (AI-2, Scheme 1) in facilitating cell-cell communication within the rhizosphere microbiome."

"The conventional approaches to $\alpha$-diketones employ expensive and sometimes toxic metals; however, the new method uses no metals and proceeds readily at sub-ambient temperatures," remarked Professor Kraus, who added: "A range of alkynes (Scheme 2) can be converted into $\alpha$-diketones and esters, aromatics and alcohols are all compatible with the mild conditions. Even unstable diketones such as 4,5-dihydroxypentane-2,3-dione, the direct precursor to AI-2, can be produced."

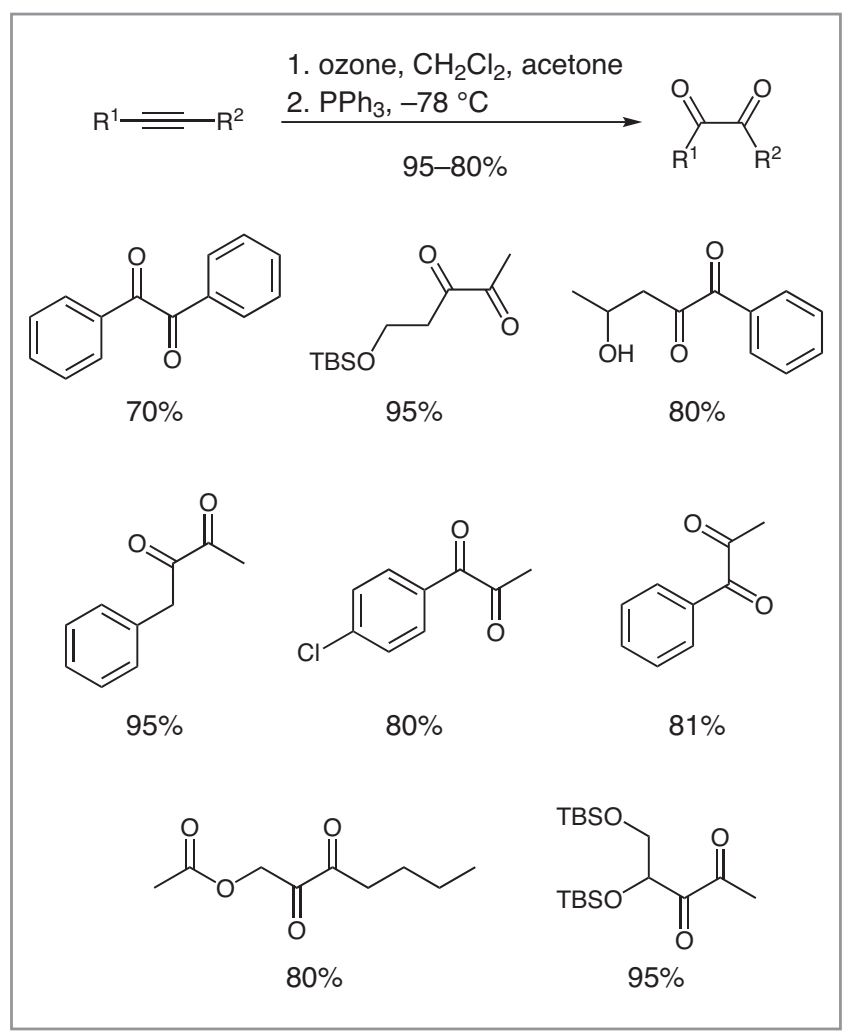

Scheme 2 Products from ozonolysis of alkynes

Interestingly, synthetic AI- 2 was confirmed to be biologically active, effectively inducing bioluminescence upon treatment of a Vibrio campbellii BB170 reporter strain known to

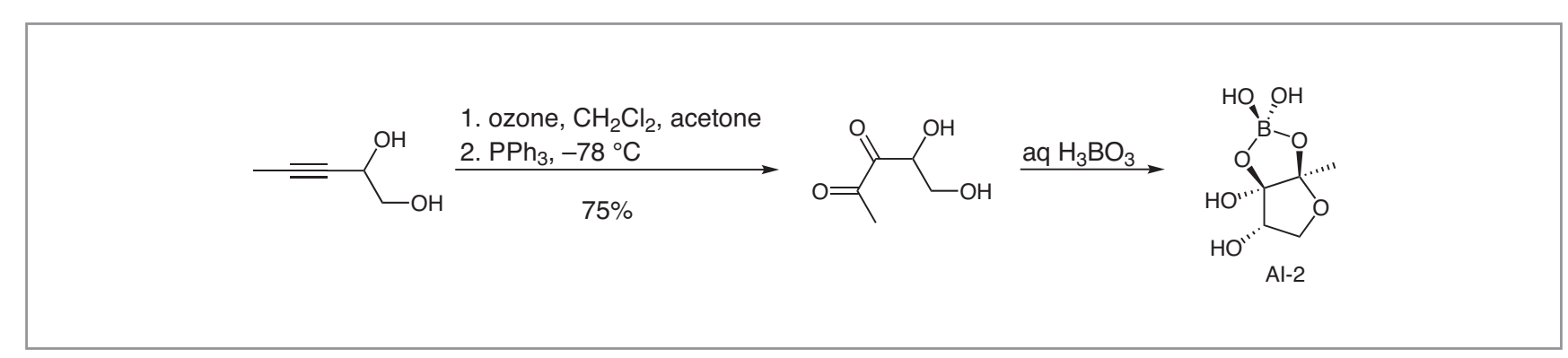

Scheme 1 Conversion of alkyne diol into Al-2 
produce bioluminescence in response to exogenously supplied AI-2 (Figure 1).

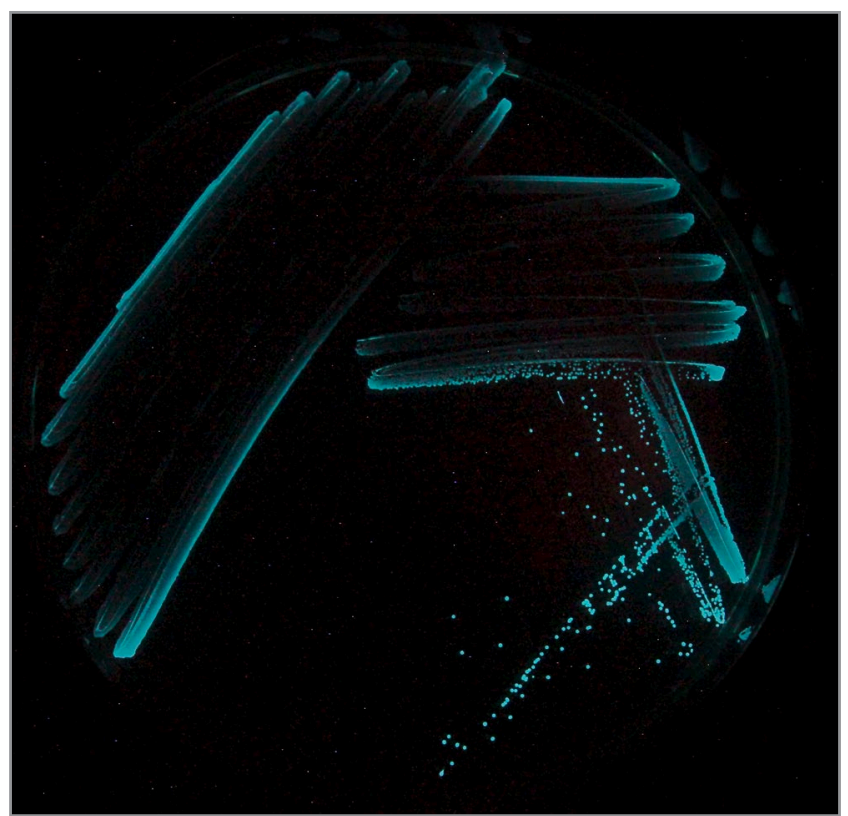

Figure 1 Vibrio cambellii BB170 grown on solid media supplemented with $\mathrm{Al}-2$

"This work provides a general entry to functionalized $\alpha$-diketones and a direct route to furanosyl borate diester (AI2), a signal molecule for inter-species quorum sensing," concluded Professor Kraus.

$$
\text { hattes tamo }
$$

\section{About the authors}

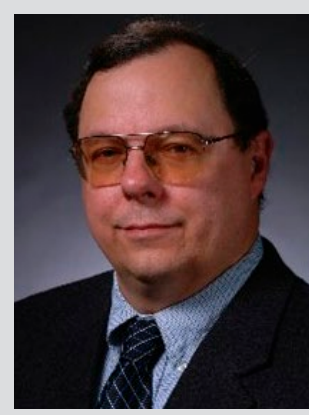

Prof. George Kraus received a B.S. degree in chemistry from the University of Rochester (USA) in 1972, and earned a PhD in chemistry from Columbia University (USA) in 1976. Immediately thereafter, he began his independent research career at lowa State University (USA), where he is now tenured and was recently appointed as a University Professor of Chemistry. His group has had a longstanding interest in new Dr. R. L. Reyes synthetic reactions and their application to the synthesis of
biologically active natural products, green chemistry and biobased products. He is the author of over 350 peer-reviewed scientific articles and the recipient of numerous awards including the Alfred P. Sloan Foundation fellow, DuPont Young Faculty Award, 3M Young Faculty Award, and Frasch Award. He is a Fellow of the AAAS.

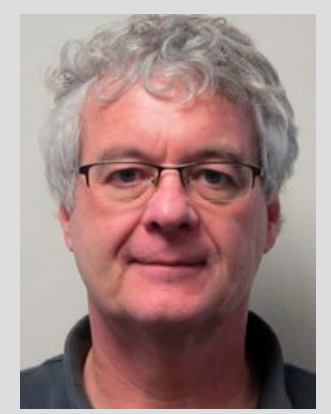

Prof. L. Halverson
Prof. Larry Halverson received a B.A. degree in biology and chemistry from Luther College (USA) in 1981 and earned an MS degree in microbiology at the University of Tennessee-Knoxville (USA) in 1983 and $\mathrm{a} P \mathrm{PhD}$ in the Institute for Environmental Studies at the University of Wisconsin-Madison (USA) in 1981. He conducted post-doctoral research at the University of California-Berkeley (USA) in soil microbial ecology. He began his independent research career at lowa State University (USA) in 1995, where he is now tenured in the Department of Plant Pathology and Microbiology. His group has had a longstanding interest in the interface between microbial ecology, microbial physiology, and synthetic biology. His research has focused on developing biosensors to interrogate microbial habitats and physiological conditions, elucidating mechanisms contributing to biofilm formation, enhancing lipid accumulation in algae for biofuels production, and characterizing soil, rhizosphere, and aquatic microbiomes. He is the author of over 40 peer-reviewed scientific articles. 


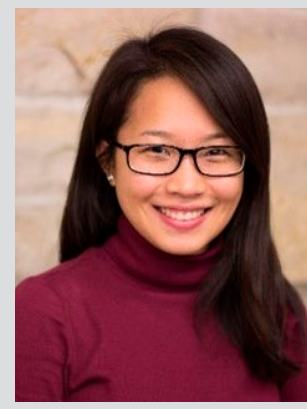

D. Vang
Dua Vang is from Minneapolis, Minnesota (USA). She received her B.A. degree in biology at Saint Olaf College (USA) in 2018. She is currently pursuing her Ph.D. in the Interdepartmental Microbiology program under the guidance of Prof. Larry Halverson at lowa State University (USA). Her current research interest is to characterize the genetic and metabolic mechanisms that contribute to microbiome assembly and bacterial fitness in the rhizosphere of maize.

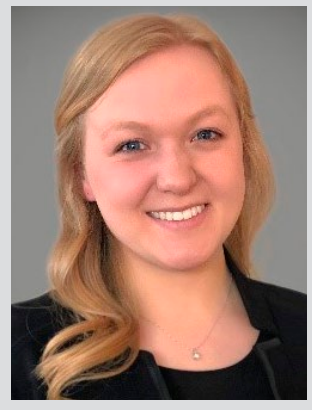

Marissa Roghair Stroud studied at lowa State University (USA) and obtained a B.S. degree in genetics and microbiology with honors in 2019. She is currently pursuing her Ph.D. at lowa State University in the Interdepartmental Microbiology program, joining Prof. Halverson's lab in 2020. Her current research interests are to understand how microbe-microbe M. R. Stroud interactions and microbial communication facilitate the ecology and fitness of bacteria during microbiome assembly in the maize rhizosphere. 


\section{Migratory Functionalization of Unactivated Alkyl Bromides for Construction of All-Carbon Quaternary Centers via Transposed tert-C-Radicals}

Nat. Commun. 2020, 11, 4860

All-carbon quaternary centers are ubiquitous in natural products and pharmaceuticals, as well as functional materials. "Conceptually, tertiary-C-C cross-coupling constitutes one of the most concise and straightforward approaches to access structures with spherical groups," explained Professor Chao Feng (Nanjing Tech University, P. R. of China). He continued: "However, the apparent steric repulsion and potential $\beta$-hydride elimination severely impede the development of this strategy. Established protocols have focused mainly on functionalization of tertiary alkyl nucleophiles (alkyl-Mg, Zn and B), or electrophiles (alkyl halides/pseudohalides), but limited functional groups or coupling partners can typically be used. Furthermore, the unwanted regioisomers deriving from isomerization of the metallic tert-alkyl intermediate were often obtained, together with the target product. Therefore, developing general methods for novel types of $\mathrm{C}-\mathrm{C}$ bond formation at the sterically demanding tertiary carbons from easily available starting materials is highly appealing." Recently, a collaborative effort between the group of Professor Feng and that of Professor Patrick J. Walsh (University of Pennsylvania, USA) uncovered a way of constructing all-carbon quaternary-center-embedded frameworks from unactivated primary/secondary alkyl bromides via a $\mathrm{Ni}-\mathrm{H}$ engaged chain-walking event (Scheme 1). "This transformation provides a mechanistically distinct and efficient entry to the three-dimensional structures with good regioselectivity, thus complementing the existing catalytic accesses," said Prof. Feng, who continued: "Moreover, this finding advances the boundary of chain-walking-associated remote functionalization. By exploiting the usually undesired $\beta$-H elimination and reinsertion of metal hydrides, transition-metal catalysts (Pd, Ni, Co, Rh, etc.) are able to move to a remote position relative to the initial metalation site, thus enabling migratory functionalization."

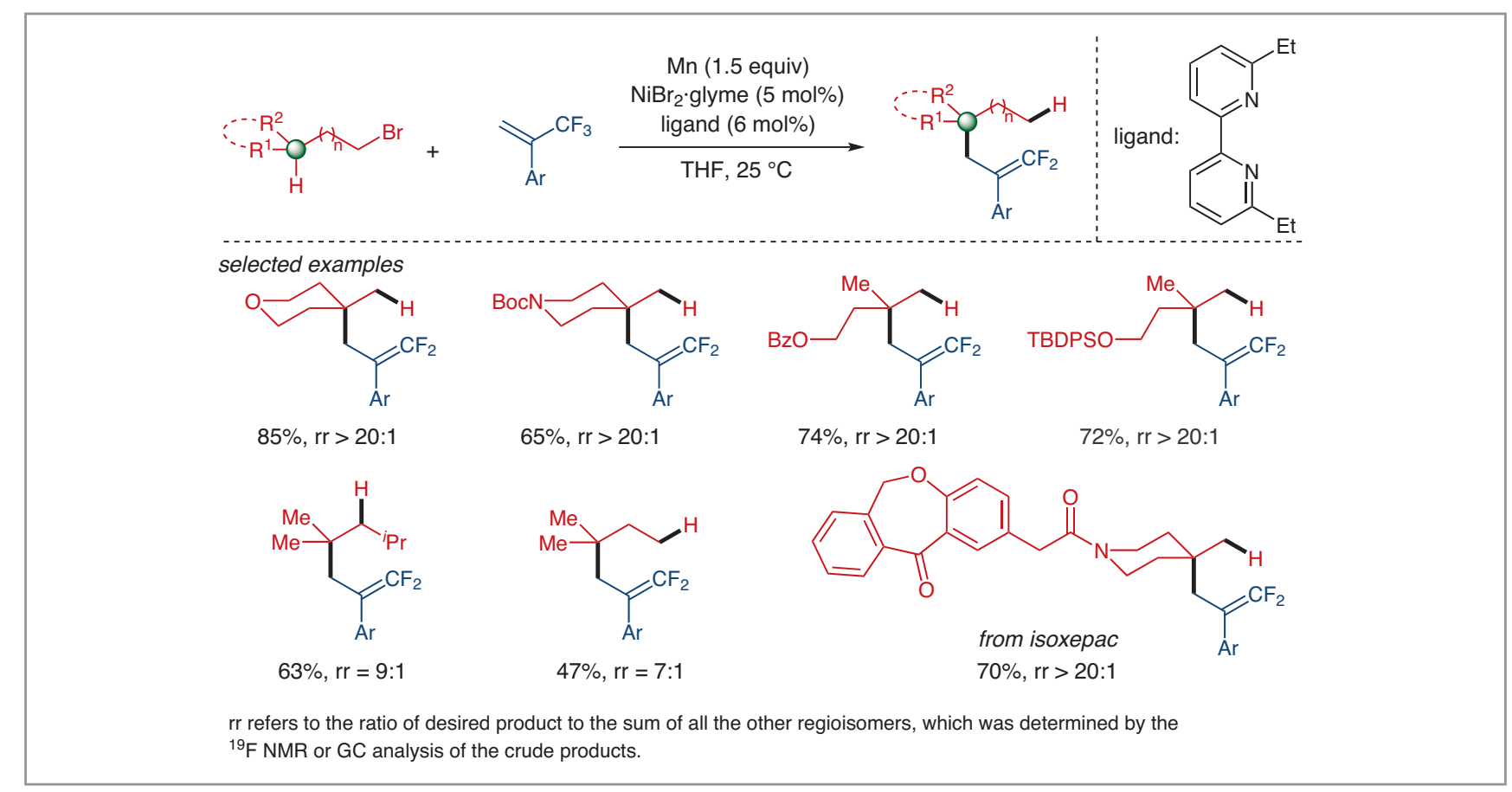

Scheme 1 Construction of all-carbon quaternary centers via migratory functionalization 
"As demonstrated by Martin (ICIQ, Spain), Zhu (Nanjing University, P. R. of China), and others, ${ }^{1-4}$ the viable remote sites include $C\left(\mathrm{sp}^{3}\right)$ centers positioned $\alpha$ to aromatics, boron, carbonyls, and primary $\mathrm{C}\left(\mathrm{sp}^{3}\right)$, which offer more stabilized carbon-metal bonds throughout the carbon chain," added Professor Feng. "In contrast, the method proposed in this paper takes advantage of the less stabilized positions, which could furnish the $\mathrm{C}$-centered radicals and undergo subsequent functionalization, thus allowing unprecedented migratory functionalization." Prof. Feng explained: "In this perspective, a formal radical rearrangement is achieved through a chainwalking process, which is usually observed only with carbocations. The 3,3-difluoroallyl represents a new functionality that could be accommodated in $\mathrm{Ni}-\mathrm{H}$-engaged catalytic systems."

As demonstrated in prior work by the Feng group, the strongly electron-withdrawing fluorine substituents render the $\mathrm{C}=\mathrm{C}$ bond resistant to the electrophilic Ni-H complex. "In addition, the successful expansion to Giese-type reaction with other electron-deficient olefins, such as acrylate, enone and acrylonitrile, emphasizes the versatility of this protocol," said Professor Feng, who concluded: "This is just the first episode of this unique chain-walking-enabled functionalization at tertiary carbons, and some even more elegant techniques to precisely distinguish between inherently similar tertiary, secondary, and primary carbons are expected based on this strategy."

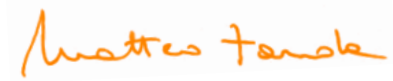

\section{REFERENCES}

(1) Benzylic position towards migration: Y. He, Y. Cai, S. Zhu J. Am. Chem. Soc. 2017, 139, 1061-1064.

(2) Primary $\mathrm{Csp}^{3}$ towards migration: F. Zhou, J. Zhu, Y. Zhang, S. Zhu Angew. Chem. Int. Ed. 2018, 57, 4058-4062.

(3) Borylated $\mathrm{Csp}^{3}$ towards migration: Y. Zhang, B. Han, S. Zhu Angew. Chem. Int. Ed. 2019, 58, 13860-13864.

(4) Primary $\mathrm{Csp}^{3}$ towards migration: F. Juliá-Hernández, T. Moragas, J. Cornella, R. Martin Nature 2017, 545, 84-88.

\section{About the authors}

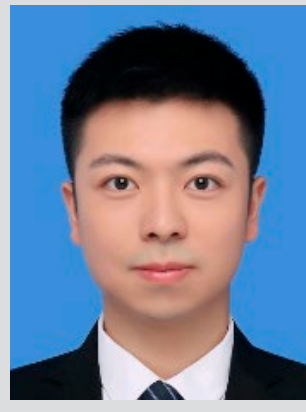

Ze-Yao Liu studied chemistry at Nanjing Tech University (P. R. of China) and earned his Bachelor's degree in 2018. Currently, he is an MSc student under the supervision of Prof. Chao Feng at NJTech. His research is focused on $\mathrm{Ni}$-catalyzed cross-coupling with fluorinated building blocks.

Z-Y Liu

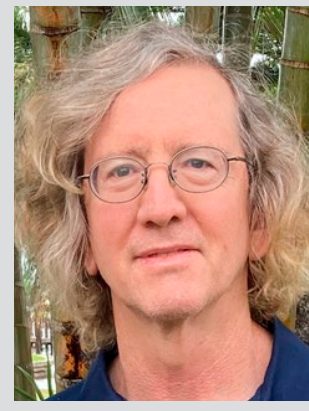

Patrick J. Walsh received his B.A. from University of California San Diego and his Ph.D. at University of California Berkeley (USA) with Prof. Robert G. Bergman (1991). He was a postdoctoral researcher with Prof. K. B. Sharpless at Scripps (USA, 1994-1999) and a professor at Centro de Graduados e Investigación, Instituto Tecnológico de Tijuana (Mexico, 1996-1999). In 1999 he moved to the University of Prof. P. J. Walsh Pennsylvania (USA). Prof. Walsh has held honorary positions
in China, including Nanjing Tech University (P. R. of China).

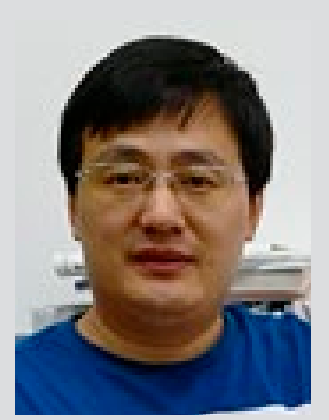

Chao Feng studied chemistry at Nanjing University of Science and Technology (P. R. of China) and received his MSc degree in 2007 under the supervision of Prof. Chun-Xu Lv. Then he moved to Nanyang Technological University (Singapore) and obtained his PhD under the supervision of Prof. TeckPeng Loh in 2012. After four years Prof. C. Feng of postdoctoral research in Prof. Loh's group, he started his independent work and became a full professor at Nanjing Tech University (P. R. of China) from 2016. In 2017, he was granted the Thieme Chemistry Journals Award. His research interests include fluorine chemistry and photoredox catalysis. 


\title{
Young Career Focus: Dr. Debasis Banerjee (Indian Institute of Technology Roorkee, India)
}

\author{
Background and Purpose. SYNFORM regularly meets young up-and-coming researchers who are \\ performing exceptionally well in the arena of organic chemistry and related fields of research, in order \\ to introduce them to the readership. This Young Career Focus presents Dr. Debasis Banerjee \\ (Indian Institute of Technology Roorkee, India).
}

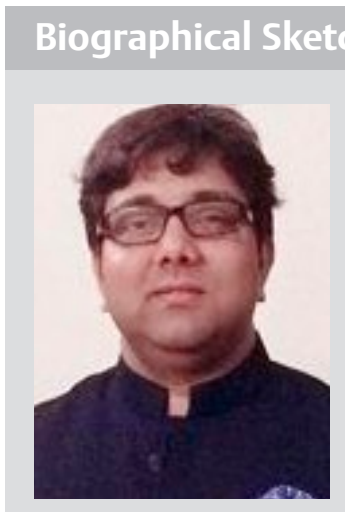

Dr. D. Banerjee
Debasis Banerjee grew up at Asansol (Hatinal), West Bengal, India. He graduated with an M.Sc. degree in organic chemistry from Banaras Hindu University and obtained his Ph.D. in organic chemistry from the Indian Institute of Technology Kanpur in 2011 under the supervision of Prof. M. L. N. Rao. Thereafter he moved to the Leibniz Institute for Catalysis (LIKAT) in Germany for a postdoctoral position with Prof. Matthias Beller (2011-2014) and subsequently held another postdoctoral position (2014-2015) at Stockholm University (Sweden) with Prof. Jan-Erling Bäckvall. In 2015, he accepted the position of Assistant Professor at the Indian Institute of Technology Roorkee (Uttarakhand, India). Currently he is an Associate Professor at the same institute from August 2020. His research interests include design and synthesis of non-precious-metal catalysts, enantioselective dual-catalysis, activation of small molecules, activation and functionalization of $\mathrm{sp}^{3} \mathrm{C}-\mathrm{H}$ bond and heterogeneous catalysis for sustainable organic transformations. He is a recipient of the SERB-Early Career Research Award (2016), the DAEYoung Scientist Research Award (YSRA-2016) and the Evonik Call for Research Proposal (ECRP-2016) Award by Evonik Industries GMBH, Germany. He was recently selected for the Thieme Chemistry Journals Award 2020.

\section{INTERVIEW}

SYNFORM What is the focus of your current research activity?

Dr. D. Banerjee My group's research is centered on the sustainable development using non-precious-metal catalysts (Fe, Ni or Mn) as the key for industrial applications. We focus on the efficient utilization of renewable raw materials, designing atom-efficient synthetic methods and avoiding the use of multi-step synthesis. I find it most exciting to design a synthesis route which eliminates stoichiometric waste production.

\section{SYNFORM When did you get interested in synthesis?}

Dr. D. Banerjee I developed an interest in organic chemistry in high school. Later on, during my bachelor's and master's studies, we were taught organic chemistry by excellent professors, which significantly enhanced my fascination with organic synthesis. Moreover, during the course of my doctoral and post-doctoral studies I got to know about various field of organic chemistry and learned incredible possibilities of research in the area of organic synthesis.

SYNFORM What do you think about the modern role and prospects of organic synthesis?

Dr. D. Banerjee A wide variety of chemical feedstocks and fuels are derived from fossil resources. Therefore, depletion of natural resources and fossil feedstocks has raised serious environmental concerns. Thus, there is a potential challenge to find alternative pathways to overcome such problems. One such alternative might be the use of renewable lignocellulosic materials for a sustainable future. However, the biggest synthetic challenge would be 'Waste to Wealth', namely to reuse and recycle our valuable resources following environmentally benign technology. 
SYNFORM Could you tell us more about your group's areas of research and your aims?

Dr. D. Banerjee A recent trend in catalysis research is to replace precious-metal catalysts using non-precious transition metals of comparable efficiency. In this direction, we made an outstanding contribution in the homogeneous $\mathrm{Ni}$-, $\mathrm{Fe}-$, and Mn-based catalyst system following a hydrogen-auto-transfer principle. Presently, at IIT Roorkee, our research group independently developed several challenging catalytic problems based on nickel catalysis for sustainable organic transformations using biomass-derived and inexpensive renewable alcohols. For instance, we made an important contribution in the areas of amination, amidation, construction of $\mathrm{N}$-heterocycles (pyrroles, pyridines, quinolines, indoles, quinoxalines, and benzimidazoles). All of these $N$-heterocycles are highly important motifs in pharmaceuticals and drugs. Thereafter, activation of the weak $\mathrm{sp}^{3} \mathrm{C}-\mathrm{H}$ bond of 2-alkylheteroarenes with alcohols and functionalization of ketone enolates with alcohols were developed. In all these areas, our research group managed easily to contribute some original chemistry. Our goal is to develop environmentally benign technologies using earth-abundant-metal catalysts in combination with renewable resources (Scheme 1).

SYNFORM What is your most important scientific achievement to date and why?

Dr. D. Banerjee One of our most important scientific achievements to date is the development of bifunctional nickel catalysis following a hydrogen-borrowing strategy. In general, nickel catalysts are known for hydrogenation reactions. Unfortunately, the bifunctional nature of the nickel catalysts was not well developed in earlier studies. It was believed that the

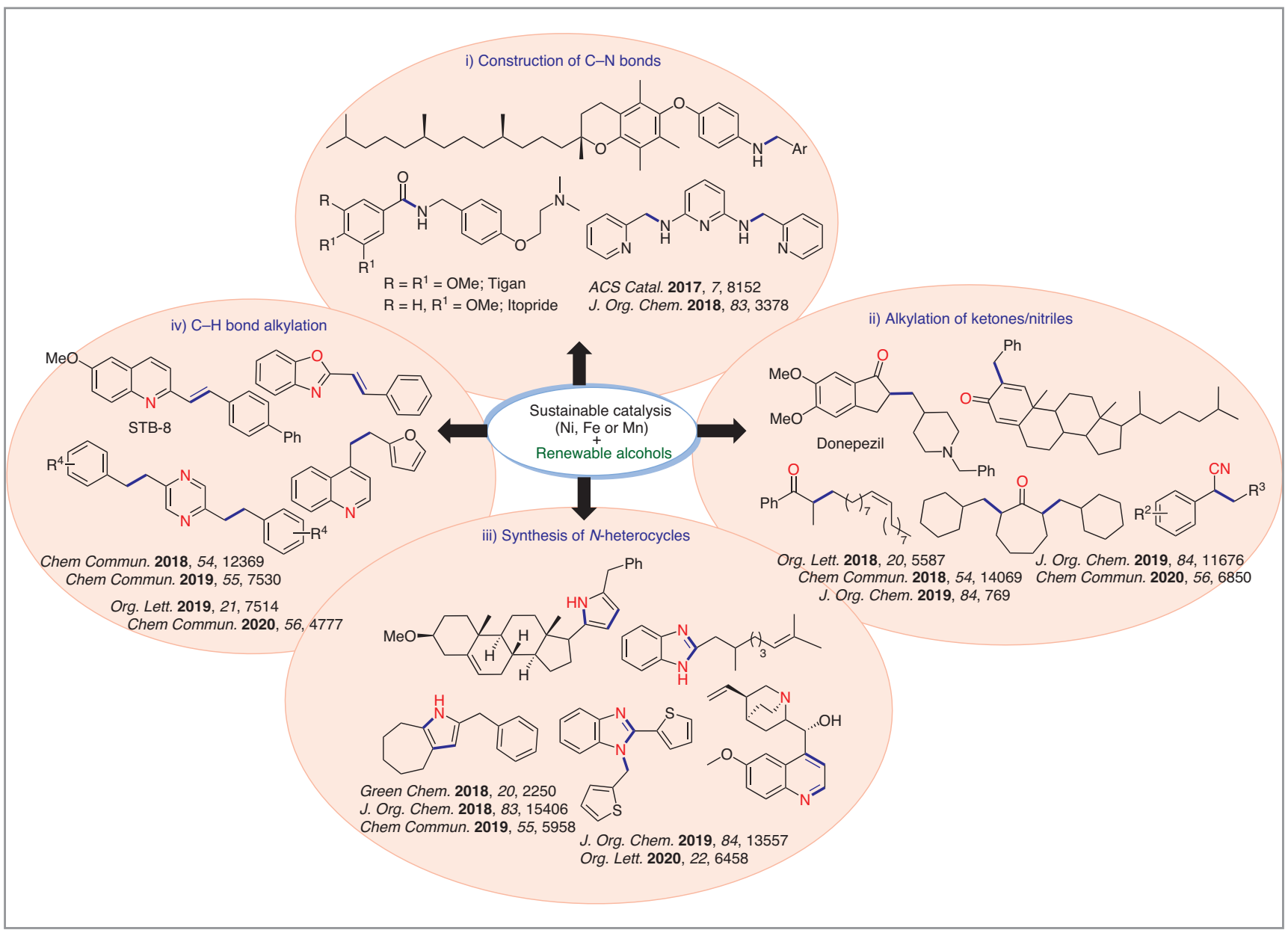

Scheme 1 Banerjee lab research overview 
free hydroxy group of alcohols would retard nickel-catalyzed transformations owing to their strong binding affinity with nickel. In this context, for the first time we demonstrated the bifunctional nature of nickel catalysts involving hydrogenborrowing approaches. Moreover, this study established a starting point in our group and we developed several interesting chemistries using nickel-based catalytic systems for the efficient and highly selective synthesis of amines, amides, and biologically interesting heterocycles using free alcohols, diols or amino alcohols (ACS Catal. 2017, 7, 8152-8158).

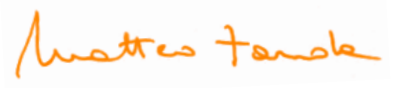




\section{Coming soon}

- Literature Coverage

Semiconductor Photoredox Catalysis to Engineering Deuterated $\mathrm{N}$-Alkyl Pharmaceuticals

Literature Coverage

Nickel-Catalyzed Mono-Selective $\alpha$-Arylation of Acetone with Aryl Chlorides and Phenol Derivatives

- Literature Coverage

Cyclodepsipeptide Alveolaride C: Total Synthesis and Structural Assignment

\section{Further highlights}

\section{Synthesis Review: Recent Advances in One-Pot Enyne} Metathesis Processes for the Preparation of Biologically and Medicinally Relevant Compounds

(by M. Serra and co-workers)

\section{Synlett Account: Recent Advances in Radical-Involved} Alkynylation of Unactivated C( sp $\left.^{3}\right)-\mathrm{H}$ Bonds by Hydrogen Atom Abstraction

(by Z.-L. Li, X.-Y. Liu and co-workers)

Synfacts Synfact of the Month in category "Metals in Synthesis": Preparation of Primary Sulfonamides by $t$-BuONSO and Organometallics
Editor

Matteo Zanda

C.N.R. - Istituto di Scienze e Tecnologie Chimiche (SCITEC)

Via Mancinelli, 7, 20131 Milano, Italy

Editorial Assistant: Alison M. Sage, synform@outlook.com

Editorial Office

Senior Director:

Susanne Haak, susanne.haak@thieme.de

Scientific Editors:

Stefanie Baumann, stefanie.baumann@thieme.de

Selena Boothroyd, selena.boothroyd@thieme.de

Michael Binanzer, michael.binanzer@thieme.de

Giuliana Rubulotta, giuliana.rubulotta@thieme.de

Kathrin Ulbrich, kathrin.ulbrich@thieme.de

- Acquisition Editor:

Juan Zhang, juan.zhang@thieme.com

- Senior Production Manager:

Thorsten Schön, thorsten.schoen@thieme.de

- Senior Production Editor:

Thomas Loop, thomas.loop@thieme.de

- Production Assistant:

Tobias Brenner, Tobias.brenner@thieme.de

Editorial Assistant:

Sabine Heller, sabine.heller@thieme.de

Marketing Director:

Julia Stötzner, julia.stoetzner@thieme.de

Postal Address: Chemistry Journals, Editorial Office, Georg Thieme Verlag KG,

Rüdigerstraße 14, 70469 Stuttgart, Germany.

Homepage: www.thieme-chemistry.com

Publication Information

Synform will be published 12 times in 2021 by Georg Thieme Verlag KG, Rüdigerstraße 14, 70469 Stuttgart, Germany, and is an additional online service for Synthesis, Synlett and Synfacts.

\section{Product Names}

Product names which are in fact registered trademarks may not have been specifically designated as such in every case. Thus, in those cases where a product has been referred to by its registered trademark it cannot be concluded that the name used is public

domain. The same applies to labels, names or other signs.

Ordering Information for Synthesis, Synlett and Synfacts

The Americas: Thieme New York, 333 Seventh Avenue, New York, NY 10001, USA.

Via e-mail: customerservice@thieme.com

Via website: www.thieme-chemistry.com

Phone: +1 212760 0888; Fax: +1 2129470108

Order toll-free within the USA: +18007823488

Europe, Africa, Asia, and Australia: Georg Thieme Verlag KG, Rüdigerstraße 14

70469 Stuttgart, Germany.

Via e-mail: customerservice@thieme.de

Via website: www thieme-chemistry.com

Phone: +49 7118931 421; Fax: +49 7118931410

Current list prices are available through www.thieme-chemistry.com.

Online Licensing Information

The online versions of Synform as well Synthesis, Synlett, Synfacts and SynOpen are available through www.thieme-connect.com/products/ejournals/journals) where it is also possible to register for a free trial account. For information on multi-site licenses and pricing for corporate customers, as well as backfiles, please contact our regional offices:

The Americas: esales@thieme.com, phone: +1 2125844695

Europe, Africa, Asia (ex. India), and Australia: eproducts@thiemede,

phone: +497118931407

India: eproducts@thieme.in, phone+911204556600

Manuscript Submission to Synthesis, Synlett, and SynOpen

Manuscript submissions will be processed exclusively online via

http://mc.manuscriptcentral.com/synthesis, http://mc.manuscriptcentral.com/synlett and http://mc manuscriptcentral.com/synopen, respectively. Please consult the Instructions for Authors before compiling a new manuscript. The current version and the Word template for manuscript preparation are available for download at www.thieme-chemistry.com.

Ownership and Copyright

(C) 2021. Thieme. All rights reserved.

This publication, including all individual contributions and illustrations published therein, is legally protected by copyright for the duration of the copyright period. Any use,

exploitation or commercialization outside the narrow limits set by copyright legislation, without the publisher's consent, is illegal and liable to criminal prosecution. This applies in particular to photocopy reproduction, copyright, cyclostyling, mimeographing or duplication of any kind, translating, preparation of microfilms, and electronic data processing and storage (CD-ROM, DVD, USB memory stick, databases, cloud-based service, ebook and other forms of electronic publishing) as well as making it available to the public (e.g. internet, intranet or other wired or wireless data networks), in particular by displaying on stationary or mobile visual display units, monitors, smart phones, tablets or other devices by download (e.g., e-pub, PDF, App) or retrieval in any other form.

Copyright Permission for Users in the USA

Authorization to photocopy items for internal or personal use, or the internal or personal use of specific clients, is granted by Georg Thieme Verlag KG Stuttgart - New York for libraries and other users registered with the Copyright Clearance Center (CCC) Transactional Reporting Service; www.copyright.com. For reprint information in the USA, please contact: journals@thieme.com
SYNFORM issue 2021/03 is available from February 16, 2021

at www.thieme-connect.com/ejournals 